\title{
What are women stressed about after birth?
}

\author{
Susan Ayers ${ }^{1}$, Rosalind Crawley ${ }^{2}$, Rebecca Webb ${ }^{1}$, Susan Button $^{3}$, Alexandra Thornton ${ }^{1}$, \\ and the HABiT collaborative group
}

Word count 3995

${ }^{1}$ Centre for Maternal and Child Health Research, City, University of London, London, EC1V 0HB.

${ }^{2}$ School of Psychology, University of Sunderland, Sunderland. SR2 7PT.

${ }^{3}$ Department of Adult Nursing and Paramedic Science, University of Greenwich, Avery Hill

Road, London, SE9 2UG.

\section{Corresponding author:}

Susan Ayers, Centre for Maternal and Child Health Research, School of Health Sciences, City, University of London, Northampton Square, London, EC1V 0HB. Email: susan.ayers@city.ac.uk Telephone 00442070405834

Word count: 3988 


\section{Acknowledgements:}

The HABiT Collaborative Group comprised Helen Smith, Robert Bradley, Suzanne Lee, Donna Moore, Andy Field, Andrew Eagle and Gill Gyte. This study was funded by the National Institute for Health Research (NIHR) Research for Patient Benefit (project reference PB-PG-021124096). The views expressed are those of the authors and not necessarily those of the NIHR or the Department of Health and Social Care. 


\section{What are women stressed about after birth?}

\section{Abstract}

Background: Having a baby is associated with a variety of stressors, change and adjustment. This study aimed to identify what women find stressful during the early postpartum period in contemporary Western society.

Methods: Women $(n=148)$ 6-12 weeks postpartum wrote anonymously about a situation they found stressful as part of the Health after Birth Trial of expressive writing. Transcripts were analyzed for categories of stressors and cross-cutting themes.

Results: Five categories of stressors were identified. Stressors in pregnancy, labour and the early postpartum period (49.3\%) included physical and emotional difficulties, as well as insensitive treatment by health professionals. Stressors related to adjusting to life with a baby $(35.8 \%)$ included difficulties coping with a new baby, parenting, juggling responsibilities, changes to physical health, and loneliness. Stressors related to the baby's health (32.4\%) included infant digestive problems, acute health problems, long-term impact, and Neonatal Intensive Care Unit experiences. Stressors related to breastfeeding (23.7\%) included pressure to breastfeed, feeling like a 'bad mum' for not breastfeeding, or wanting to breastfeed and not being able to. Other stressors related to changing relationships (18.2\%): with their partner, children and other family members. Cross-cutting themes that emerged in different stressor categories were women making negative self-appraisals (e.g. a bad mum, failure), feeling guilty, and lack of support from others.

Discussion: Our findings emphasise the importance of exploring stressors and psychological well being with women to provide support, help women's adjustment postpartum, and ensure interventions are offered when appropriate. 
Introduction

Pregnancy, birth and becoming a parent is a time of physical, psychological, and social changes which require ongoing adjustment. Many stressors can arise during this time which may impact on women, their infant, and their relationships ${ }^{1,2}$. Research investigating women's worries during pregnancy suggests women worry about how they will cope as new parents, ${ }^{3}$ the impact on their relationship, ${ }^{4,5}$ childbirth, ${ }^{6-9}$ the baby's health, ${ }^{6,8-11}$ and the impact of their own health and behaviour in pregnancy on the baby. ${ }^{6}$ Postpartum, women report worries about breastfeeding. Research suggests women feel a lot of pressure to breastfeed, ${ }^{12}$ that they expect it to be easy and natural, and feel guilty if they stop breastfeeding. ${ }^{13}$ Women also report worrying about their infant getting enough milk. ${ }^{14}$ In relation to motherhood, women report worries about their ability to bond with their baby, ${ }^{15}$ care for their baby, ${ }^{16}$ and be a good mother. ${ }^{15,17}$ Women also have concerns about their ability to cope with the demands of their baby, ${ }^{18,19}$ the housework, their partner, and other children. ${ }^{20}$ In terms of self-care women report feeling sleep deprived, exhausted, ${ }^{19,20}$ and not being able to have time to themselves. ${ }^{19}$ Women also report feeling pressure to regain their pre-baby figure. ${ }^{15}$

This research suggests women experience a variety of worries which may contribute to the development of psychological problems. ${ }^{21}$. However, although worries are associated with stressors they are an indirect measure. Worries are conscious, verbal cognitions, usually about future negative events, that are associated with negative emotions. Stressors are external or internal events that trigger stress responses. ${ }^{22}$ Much of the research focuses on worries about specific factors, such as breastfeeding or labour, rather than asking women about any stressor they experience. Research tends to use quantitative measures, such as the Cambridge Worry Scale, ${ }^{23}$ which measure pre-defined worries and therefore restrict the range of stressors women 
can report. Questionnaires and interviews may also be subject to reporting bias if women are concerned about stigma or social judgement. ${ }^{24}$

The current study aimed to address these methodological issuess by identifying key stressors during the perinatal period, using a method that encourages open and honest reporting. Stressors were identified using an anonymous expressive writing task where postpartum women wrote about an event or difficulty they found stressful or upsetting. This event could have been related to pregnancy, birth, the baby, or to something else going on in their lives. This was conducted as part of the Health after Birth Trial (HABiT), a randomised controlled trial (RCT) of the effectiveness of expressive writing for postpartum health. ${ }^{25,26}$ Analysing the events women wrote about provides the opportunity to identify key stressors women experience in the early postpartum period in contemporary Western society.

\section{Methods}

We did a content analysis and thematic analysis of the stressors reported 6-12 weeks after birth by women who took part in the HABiT RCT of expressive writing. Recruitment took place in 14 NHS hospitals in England from November 2013 to December 2014. Women were eligible to participate if they were aged 18 years or older and had given birth to a live infant after 26 weeks gestation. Women who experienced stillbirth or neonatal death prior to hospital discharge were excluded. All eligible women who gave birth at the NHS hospitals during the study period were invited to participate: 1,413 women replied and 854 consented to participate. Of these, 319 women were allocated to the expressive writing condition and 148 completed the expressive writing task 6-12 weeks after birth. Additional details on sampling, recruitment, and attrition for HABiT are reported elsewhere. ${ }^{25,26}$ 
Ethical approval was obtained from an NHS Research Ethics Committee. All eligible women were sent a letter 4-6 weeks after birth inviting them to participate in the study, along with a participant information leaflet, consent form, and reply-paid envelope. Women who wanted to take part were asked to provide their contact details and complete the consent form. Women could participate online or using a workbook. Women who requested online were enrolled on an online system and sent an email or text message with their username and password. Women who did not log on received reminder emails or text messages after seven days. Women who requested a workbook were sent the workbook with a reply-paid envelope. If they did not return the workbook within 10 days they were sent reminders by post, email, or text message. Reminder times were slightly longer for workbook participants to take account of the delay between postage and receipt of the workbooks.

The expressive writing task was based upon Pennebaker's expressive writing paradigm. ${ }^{27,28}$ Women were instructed to write for 15 minutes each day for three days about "an event or difficulty that you have found stressful or upsetting. This might be something about your pregnancy, birth, baby, or might be something else going on in your life". Women were asked to write about their "deepest thoughts and feelings" about this event. To avoid re-traumatising women who had suffered traumatic events, the instructions stated that if writing about this event felt too distressing or overwhelming women should pick a less stressful event. Women were asked to write on three consecutive days but, if they missed a day, to try to complete all three writing exercises within a week. The date and time they started and stopped writing was recorded automatically (online) or by self-report (workbook). Previous analyses showed this writing task was acceptable to women. ${ }^{26}$ 
Before and after writing women were asked to rate "How upset or stressed are you by this event or difficulty now?" on a 10-point scale from 1 (not at all) to 10 (extremely) which provided a measure of perceived stress. Demographic measures of age, marital status, education, ethnicity, and employment were completed at the end of the expressive writing task.

\section{Analysis}

Women's writing from the first day was used to analyse the stressors women reported using content analysis (to identify categories of stressors) and thematic analysis (to identify cross-cutting themes). Texts were anonymised with personally identifiable information removed or replaced e.g. [baby] to replace the baby's name. Participants were identified by a unique participant number. Texts were analysed using NVivo software. ${ }^{29}$ All written accounts were read and the main stressor(s) women wrote about coded e.g. baby in NICU. Codes were then put into broad categories (e.g. problems with the baby's health) and subcategories identified on the basis of content and frequency. This was used to develop a coding schedule which was then applied to all texts. Categories and quotes were examined to identify cross-cutting themes. Initial coding was conducted by one author (RW), the coding schedule was developed by two authors (RW, SA), and cross-cutting themes were identified and agreed by three authors (RW, SA, RC).

\section{Results}

Women's age ranged from 21-42 (Mean=32.1 years, $\mathrm{SD}=5.2$ ). The majority were White European $(94.3 \%)$, followed by Asian (2.8\%), other (1.9\%), and African ( $0.9 \%)$. The majority were married $(62.5 \%)$ or cohabiting (33.7\%). Many women were educated to degree level (43.2\%) and only two women had no educational qualifications (1.4\%). Most were in employment (83\%) and in professional occupations $(53 \%) .{ }^{30}$ 
Five categories of stressors were identified and are shown in Table 1 with frequency and mean stress ratings. Stress ratings for most categories ranged from 1-10 with a mean of 5.5 (SD 2.8), suggesting moderate levels of stress.

- Table 1 -

\section{Category 1: Stressors in pregnancy, birth, or the early postpartum period}

Seventy-three women (49.3\%) wrote about stressors in pregnancy, birth or the early postpartum period. The most common were stressors in labour and birth, which were reported by $23.7 \%$ of the total sample. Women wrote about difficult or traumatic births, including physical and psychological trauma, feeling out of control, being 'an accessory in delivery', feeling distant and detatched in response to difficulties in birth, not giving birth the way they wanted to, and insensitive treatment by health professionals which increased women's feelings of distress.

“The whole experience really wasn't about me - I feel like more of an accessory in delivery. In fact I had no choice in the matter - my body decided this was what was going to happen and I was powerless to stop it."

"I feel very upset about how my labour was managed, in particular the attitude of one midwife... The midwife ignored me when I said that I was in labour and simply put me in a bay... I told her [midwife] I needed to push NOW! The ward sister then arrived, helped me on the bed, and did a quick exam before announcing that I was fully dilated and crowning and I needed to get to delivery suite as soon as possible. They then ran, pushing my bed down the corridor with my bottom half out for all to see."

Stressors in the early postpartum period occurred immediately after birth (e.g. postpartum haemorrhage) or as a result of birth injuries (e.g. incontinence). These were reported by $18.2 \%$ of women. 
"I really hate knowing that I can't control my bladder; that if I was not wearing an incontinence pad 24 hours a day I would wet myself constantly throughout the day. I feel humiliated by the fact that I now go through 2 packs [of pads] a week."

Similar to stressors in pregnancy and birth, poor care from health professionals was a stressor early postpartum.

"I was hyperventilating and although I'd had oxygen mask in theatre due to my asthma I was given no such support in my after care. I felt neglected and terrified...”

Fewer women wrote about stressors in pregnancy (7.4\%). Pregnancy stressors included previous pregnancy loss, emotional difficulties, insensitive care, and finding out about fetal anomalies. For example, women described being treated insensitively during pregnancy by health professionals; or the difficulty of hearing their baby had a serious condition during pregnancy.

"He then went straight to say: "I have two big problems with you - your age and the fact it's an IVF pregnancy. This means you are at a very high risk of stillbirth.” Even though I knew the risks already, the way he said it was awful."

\section{Category 2: Adjusting to life with a baby}

Fifty-three women (35.8\%) wrote about stressors related to adjusting to life with a baby. This included difficulties coping with a new baby, parenting, juggling responsibilities, changes to physical health, and loneliness. Stress of coping with a new baby was described by $16.2 \%$ of women with most reporting difficulty coping with the baby crying.

"I spend a lot of time Googling 'why does my baby cry all the time', and not getting much reassurance from what I find...When I meet strangers and they comment on how pretty she is [and] I always feel the need to tell them that she is also noisy. I don't know why I 
do this...I feel resentful sometimes of my friends with their babies who hardly ever cry...At my worst times I feel useless - surely I should be able to comfort her."

Others wrote about difficulty coping with a new baby and older children, and the guilt that can accompany this; or stressors such as difficulty trying to go out with a baby and older child.

"I feel I am neglecting him [older child] while I am dealing with [baby]. Although I know deep down he is not scarred in any way from this and that he is perfectly happy except for decreased attention from mummy...the overriding factor is guilt."

Stress or concerns about parenting were reported by $8.8 \%$ of women. A common topic was disagreement between women and their partners over parenting. Single parents also reported stress and concerns about being judged because of being a single parent.

"We had a big row at that point because I felt that my husband didn't believe that I was making the right judgement. He has had children in the past and this is my first baby so when he takes over or suggests that what I am doing is wrong it makes me feel inadequate."

A less frequent subcategory was stressors associated with juggling responsibilities with a new baby which were reported by $4.1 \%$ of women.

"As much as you may want children, it can still be quite shocking to realise with the first one that you will never have your hands free again. Previously simple tasks are no longer simple - like just putting a load of washing on - suddenly with a baby (and pets) it becomes a logistical nightmare to make sure everyone's needs are met before you do these tasks."

The physical impact of having a new baby was written about by $4.1 \%$ of women and was almost solely about sleep deprivation and exhaustion. 
"Nothing can prepare you for the effects of tiredness...Most days I'm ok and amazed at how little sleep I can manage on, and then some days I just feel like I'm on the point of collapse."

The loneliness of motherhood was reported by $2.7 \%$ of women and had the highest mean stress rating (7.5) of all stressor subcategories.

"Since giving birth to my first child I have felt lonely. Mostly it is me who looks after the children and giving birth to my second child increased the feeling of being on my own... More and more often since giving birth I realise I have lost contact with my friends..."

\section{Category 3: Problems with the baby's health}

Forty-eight women (32.4\%) wrote about problems with their baby's health. This included digestive problems, long-term impact, serious health problems, and experiences on the Neonatal Intensive Care Unit (NICU). The most common subcategory was digestive problems where $12.2 \%$ of women reported struggling to cope with their babies' feeding or digestive problems and how this led to feelings of helplessness.

"My 8 week old daughter has colic and has had this for 4 weeks now. For hours she squeals on and off... it takes patience with myself and with her also. I find it hard not to get irritable and not to shout... I know this is not her fault and that she needs calm and comfort but I feel useless.”

Acute health concerns and feelings of fear, terror, and helplessness were described by $7.4 \%$ of women in situations such as their baby having a very high fever or vomitting blood. "I picked her up and she was boiling hot... she kept being sick and when I checked her temp it was 38.8. I told [partner] we had to go to A\&E now... I was so scared she had meningitis or was going to have a fit and then be brain damaged...I finally got her settled 
at 5.30am then I got in my bed next to her and cried because I was scared for her and scared that I couldn't cope being a mum and I wanted my mum.”

The long term impact of such health issues was a stressor for $6.1 \%$ of women who were anxious about their baby being severely ill again.

“...since then I have been worried about it happening again, so much so I couldn't sleep for the first few days after it happened and dreaded putting her down in her cot in case it happened again."

Women whose babies had congenital abnormalities also described worrying about the long-term effect on the baby.

Women (4.7\%) whose babies had been on NICU reported this as stressful, affecting their feelings about themselves, and making it harder to bond and care for their baby.

“...he was hooked up to monitors, had wires and tubes all over him, and a mask on to make sure he was breathing okay. I didn't know what he looked like, what colour hair he had, what his eyes were like... I felt useless too. I couldn’t just pick him up and hold him and look after him like a normal new parent."

\section{Category 4: Breastfeeding}

Thirty-five women (23.7\%) reported breastfeeding stressors of feeling pressured by others to breastfeed, feeling like a 'bad mum' for not wanting to breastfeed, or wanting to breastfeed and not being able to. Pressure to breastfeed was reported by $15.5 \%$ of women who wrote of finding breastfeeding 'agony', and being in 'constant pain'. Women reported feeling anxious, guilty, and desperate to give up breastfeeding but feeling like they had to continue.

"It seems like it's sold be the most natural thing in the world but it is hard work...There are so many breastfeeding Nazis out there who want to make you feel bad for bottle 
feeding, or even thinking about it, that no wonder many women, me included, feel anxious and guilty about how we feed our children.”

Another $5.4 \%$ of women wrote about feeling like a bad mum for not wanting to breastfeed, that they were letting their baby down and other people would think they were a bad mother.

"I gave up at 6 weeks and started bottle feeding whilst expressing milk until my supply dwindled at 11 weeks. At the time I felt so guilty to have let [my baby] down... I still feel I have to justify bottle feeding. Everyone has to hear my 'whole story' as to why I'm a terrible mother who bottle feeds."

Similarly, $2.7 \%$ of women reported wanting to breastfeed but not being able to and feeling upset and/or that they had failed.

“The breastfeeding really wasn't working... I had no choice but to give up on breastfeeding and combination feed with breast milk and formula. I was extremely upset about this... felt disappointed that my baby wasn't getting fed naturally... felt embarrassed telling my friends that breastfeeding had failed."

\section{Category 5: Changing relationships}

Twenty-seven women (18.2\%) wrote about changing relationships with family, partners, and other children since the birth of the baby. Most women (11.5\%) wrote about the impact on their relationship with their partner. In some cases, women felt their partner was unsupportive and should take more responsibility. Women described resentment towards their partners and finding it frustrating to have to ask for help. Many women reported having a baby had created distance between them and their partners, emotionally and physically. Women also wrote about difficult sexual relationships with their partner since birth. 
"My husband can't even take her for very long when she is colicky and this in itself frustrates me - he says it goes right through him and he can't take it. I then become angry with him. Of course it runs through you, as it does everyone, but you just have to do it. Does he not understand that if he can't do it then it is his wife that has to feel the same emotions and do it for him?"

"I just feel distant from him and that we have forgotten why we are together, except to look after our kids we both love."

A few women (2.7\%) were concerned about the impact of the new baby on their relationships with older children. Women reported feeling guilty that they could not give both children their full attention at all times.

"I do my best but I know that they want more. This makes me feel guilty sometimes but what can I do? I know my [older child] wants me to play cars with him but I also need to feed the family, tidy, wash up etc. or the family will not function."

A few women (2.7\%) wrote about how having a baby led them to reflect on relationships with family members who were uninterested or overbearing.

"Me and my mother-in-law have a 'great' relationship. We equally don't care about each other. I only catch myself lately thinking too much about the fact that she is not even interested in her own grandkids."

\section{Cross-cutting themes}

Three cross-cutting themes were identified: negative self-appraisals, feelings of guilt, and lack of support from others. Negative self-appraisals were common with women expressing negative self-appraisals in four of the five stressor categories, saying they felt they had let others down, were a bad mother, a failure, useless, or unable to cope. Reports of being a failure and a 
'bad mum' were most commonly mentioned in relation to breastfeeding stressors and problems with the baby's health. In two stressor categories negative self-appraisals were exacerbated by women thinking others would judge them badly and feeling they had to justify themselves to others. Related to this, women reported feelings of guilt across all five stressor categories, most commonly in relation to difficulties breastfeeding and adjusting to life with a baby.

The third cross-cutting theme was lack of support from others. This was most apparent in stressors during pregnancy, birth, and the early postpartum period where women reported feeling stressed by insensitive care and lack of support from health professionals. Lack of support from the baby's father or other family members was also reported in two other stressor categories.

\section{Discussion}

This study examined the stressors women experience in the early postpartum period in contempory Western society using expressive writing in a large community sample of women. Findings are broadly consistent with the literature on worries during pregnancy which suggests women worry about their baby's health, labour and birth, and the impact of the baby on their relationships. ${ }^{4-11}$ Stressors reported in the current study were almost completely specific to the perinatal period (e.g. birth, breastfeeding, baby's health) and most stressors were postpartum rather than antenatal, which is probably due to stressors being measured 6-12 weeks postpartum. Some issues identified in previous literature were not found in the current study e.g. pressure to regain pre-baby figure. ${ }^{15}$ Cross-cutting themes were also consistent with previous literature suggesting negative self-appraisals (e.g. being a bad mum) are common. ${ }^{31}$ Support is also known to be important in the postpartum period with potential direct and indirect effects on women's psychological well being. ${ }^{32}$ 
Findings need to be interpreted in light of limitations to the study. There may have been a selection bias because of the low percentage of women we approached who took part. Also, the sample was predominantly White European with many educated to degree-level or above so is not representative of the general population. Further research is needed that examines stressors in women from more diverse groups or with fewer years of education. In addition, timing of the expressive writing task 6-12 weeks after birth and the study being labelled HABiT (Health after Birth Trial), means women may have been primed to focus on birth- and postpartum-related stressors. Finally, the number of women who wrote about each stressor category should not be conflated with how common these stressors are. Women were told to write about any stressful experience so could have chosen this on the basis of different criteria e.g. most distressing, most memorable, most frequent, most recent, etc.

These findings have implications for women and health professionals. Findings show a range of perinatal-related stressors arise postpartum and moderate levels of stress are reported by women. Types of stressors are almost completely related to perinatal events, adjusting to life with a new baby, and effects on relationships. Interventions that target these stressors such as breastfeeding support, peer support, or parenting interventions may reduce stress and facilitate adaptation postpartum. Referral to different types of interventions can be informed by which stressors women experience. For example, peer support or support groups may be helpful for women struggling with loneliness. Cross-cutting themes emphasise the importance of sensitive, compassionate support from health professionals during pregnancy, birth, and postpartum for women experiencing stressors. Health professionals can explore stressors and psychological well being with women to provide individually tailored support, help women to adjust postpartum, and ensure that the right types of interventions are offered when appropriate. 
In conclusion, this study identified a range of stressors women experience in the early postpartum period which were almost all related to perinatal factors. Cross-cutting issues were women's negative self-appraisals, feeling guilty, and lack of support from others. Stressors identified are generally consistent with the literature on women's worries and factors associated with poor perinatal mental health. However, there were a few differences in emphasis and a notable lack of stressors related to physical appearance. Our findings emphasise the importance of exploring stressors and psychological well being with women to provide support, help women's adjustment postpartum, and ensure interventions are offered when appropriate. However, more research is needed in more diverse samples and outside the context of a health intervention trial. 


\section{References}

1. LaCoursiere, DY, Hirst, KP, Barrett-Connor, E. Depression and pregnancy stressors affect the association between abuse and postpartum depression. Maternal and Child Health Journal. 2012, 16(4): 929-935. doi: 10.1007/s10995-011-0816-7

2. Divney, AA, Sipsma, H, Gordon, D, Niccolai, L, Magriples, U, Kershaw, P. Depression during pregnancy among young couples: the effect of personal and partner experience of stressors and the buffering effects of social relationships. Journal of Pediatric and Adolescent Gynecology. 2012, 25(3):201-207. doi: https://doi.org/10.1016/j.jpag.2012.02.003

3. Delmore-Ko P, Pancer SM, Hunsberger B, Pratt M. Becoming a parent: The relations between prenatal expectations and postnatal experience. Journal of Family Psychology. 2000; 14(4): 625640. doi: https://doi.org/10.1037//0893-3200.14.4.625

4. Biehle SN, Mickelson KD. Worried in expectant parents: its relation with perinatal well-being and relationship satisfication. Personal Relationships. 2011; 18: 697-713. doi:

\section{https://doi.org/10.1111/j.1475-6811.2010.01335.x}

5. Pastore L, Owens A, Raymond C. Postpartum sexuality concerns among first-time parents from one U.S. academic hospital. The Journal of Sexual Medicine. 2007; 4(1): 115-123. doi: https://doi.org/10.1111/j.1743-6109.2006.00379.x

6. Gourounti K, Anagnostopoulos F, Lykeridou K, Griva F, Vaslamatzis G. Prevalence of women's worries, anxiety, and depression during pregnancy in a public hospital setting in Greece. Clinical Experimental Obstetrics \& Gynecology. 2013; 40(4): 581-583.

7. Henderson J, Redshaw M. Worries about labor and birth: A population-based study of outcomes for young primiparous women. Birth. 2016; 43(2): 151-158. doi:

https://doi.org/10.1111/birt.12219 
8. Maier B. Women's worries about childbirth: making safe choices. British Journal of Midwifery. 2010; 18(5): 293-299. doi: https://doi.org/10.12968/bjom.2010.18.5.47859

9. Ohman SG, Grunewald C, Waldenstrom U. (2003). Women's worries during pregnancy: testing the Cambridge Worry Scale on 200 Swedish women. Scandinavian Journal of Caring Sciences. 2003; 17(2): 148-152. doi: https://doi.org/10.1046/j.1471-6712.2003.00095.x 10. Ohman SG, Saltvedt S, Grunewald C, Waldenstrom U. Does fetal screening affect women's worries about the health of their baby? Acta Obstetricia et Gynecologica Scandinavica. 2004; 83(7): 634-640. doi: https://doi.org/10.1111/j.0001-6349.2004.00462.x

11. Penacoba-Puente C, Monge FJ, Morales DM. Pregnancy worries: a longitudinal study of Spanish women. Acta Obstetetricia Gynecologica Scandinavica. 2011;90(9): 1030-1035. doi: https://doi.org/10.1111/j.1600-0412.2011.01208.x

12. Forster DA, McLachlan HL. Women's views and experiences of breastfeeding: positive, negative or just good for the baby? Midwifery. 2010; 26(1): 116-125. doi:

https://doi.org/10.1016/j.midw.2008.04.009

13. Mozingo J, Davis M, Droppleman PG, Merideth A. "It wasn't working": Women's experiences with short-term breastfeeding. The American Journal of Maternal/Child Nursing. 2000; 25(3): 120-126. doi: https://doi.org/10.1097/00005721-200005000-00004

14. Chapman JJ, Macey MJ, Keegan M, Borum P, Bennett, S. Concerns of breastfeeding mothers from birth to 4 months. Nursing Research. 1985; 34(6): 374-376. doi:

https://doi.org/10.1097/00006199-198511000-00020

15. Miller T. "Is this what motherhood is all about?" Weaving experiences and discourse through transition to first-time motherhood. Gender \& Society. 2007; 21(3): 337-358. doi: https://doi.org/10.1177/0891243207300561 
16. Karin N, Sternhufvud LB. Mother's and fathers' concerns and needs postpartum. British Journal of Midwifery. 2000; 8(6): 387-394. doi: https://doi.org/10.12968/bjom.2000.8.6.8123

17. Hiser, P. L. Concerns of multipara during the second postpartum week. Journal of Obstetric, Gynecologic and Neonatal Nursing. 1987; 16(3): 195-203. doi: 10.1111/j.5526909.1987.tb01457.x

18. Barclay L, Everitt L, Rogan F, Schmied V, Wyllie, A. Becoming a mother - an analysis of women's experience of early motherhood. Journal of Advanced Nursing. 1997; 25(4): 719-728. doi: https://doi.org/10.1046/j.1365-2648.1997.t01-1-1997025719.x

19. McVeigh C. Motherhood experiences from the perspective of first-time mothers. Clinical Nursing Research. 1997; 6(4): 335-348. doi: https://doi.org/10.1177/105477389700600404

20. Harrison MJ, Hicks SA. Postpartum concerns of mothers and their sources of help. Canadian Public Health Association. 1983; 74(5): 325-328.

21. Yusuff ASM, Tang L, Binns, CW, Lee, AH. Prevalence and risk factors for postnatal depression in Sabah, Malaysia: a cohort study. Women and Birth. 2015, 28(1): 25-29. doi: 10.1016/j.wombi.2014.11.002

22. Davey GC, Wells A, editors. Worry and its psychological disorders: Theory, assessment and treatment. John Wiley \& Sons; 2006 Feb 22.

23. Green JM, Kafetsios K, Statham HE, Snowdon CM. Factor structure, validity and reliability of the Cambridge Worry Scale in a pregnant population. Journal of Health Psychol. 2003; 8(6): 753-764. doi: https://doi.org/10.1177/13591053030086008

24. van de Mortel, TF. Faking it: social desirability response bias in self-report research. Australian Journal of Advanced Nursing. 2008; 24(4): 40-48. 
25. Ayers S, Crawley R, Button S, Thornton A, Field AP, Flood C, Lee S, Eagle A, Bradley R, Moore D, Gyte G. Evaluation of expressive writing for postpartum health: a randomised controlled trial. Journal of Behavioral Medicine. 2018;41(5):614-26. doi: 10.1007/s10865-018$9970-3$

26. Crawley R, Ayers S, Button S, Thornton A, Field AP, Lee S, Eagle A, Bradley R, Moore D, Gyte G, Smith H. Feasibility and acceptability of expressive writing with postpartum women: a randomised controlled trial. BMC pregnancy and childbirth. 2018;18(1):75. doi: https://doi.org/10.1186/s12884-018-1703-7

27. Pennebaker JW, Seagal JD. Forming a story: the health benefits of narrative. Journal of Clinical Psychology. 1999; 55(10): 1243-1254. doi: https://doi.org/10.1002/(SICI)10974679(199910)55:10<1243::AID-JCLP6>3.0.CO;2-N

28. Smyth JM,Pennebaker JW. Exploring the boundary conditions of expressive writing: In search of the right recipe. British Journal of Health Psychology. 2008; 13(Pt 1): 1-7. doi: https://doi.org/10.1348/135910707X260117

29. QSR International. NVivo qualitative data analysis software. 2012; 10.

30. Office for National Statistics. Standard Occupational Classification: Volume 1 Structure and descriptions of unit groups. https://bit.ly/2FkNwLY. Published 2010. Accessed December 20, 2018.

31. Moore D, Ayers S, Drey N. A Thematic Analysis of Stigma and Disclosure for Perinatal Depression on an Online Forum. JMIR Mental Health. 2016; 3(2): e18. doi: $\underline{\text { https://doi.org/10.2196/mental.5611 }}$ 
32. Balaji AB, Claussen AH, Smith DC, Visser SN, Morales MJ, Perou R. Social support networks and maternal mental health and well-being. Journal of Womens Health. 2007; 16(10): 1386-96. doi: https://doi.org/10.1089/jwh.2007.CDC10 
Table 1

Categories of stressors reported by women 6-12 weeks after birth, number of women reporting stressors, and mean stress ratings, England, 2013-2014

\begin{tabular}{|l|l|l|}
\hline Category and subcategories & $\begin{array}{l}\text { Frequency } \\
\text { a }\end{array}$ & $\begin{array}{l}\text { Stress rating } \\
\text { Mean (range) }\end{array}$ \\
\hline Stressors in pregnancy, birth, or the early postpartum period & $73(49.3)$ & $6.1(1-10)$ \\
\hline Labour and birth & $35(23.7)$ & $5.9(1-10)$ \\
\hline Early postpartum period & $27(18.2)$ & $6.4(1-10)$ \\
\hline Pregnancy & $11(7.4)$ & $6.1(2-10)$ \\
\hline Adjusting to life with a baby & $53(35.8)$ & $5.6(1-10)$ \\
\hline Coping with a new baby & $24(16.2)$ & $5.3(2-10)$ \\
\hline Parenting & $13(8.8)$ & $5.1(2-8)$ \\
\hline Juggling responsibilities & $6(4.1)$ & $3.8(1-7)$ \\
\hline Physical impact of a new baby & $6(4.1)$ & $6.3(3-9)$ \\
\hline Loneliness & $4(2.7)$ & $7.5(3-10)$ \\
\hline Problems with the baby's health & $48(32.4)$ & $5.8(1-10)$ \\
\hline Digestive problems & $18(12.2)$ & $5.5(2-10)$ \\
\hline Acute health concerns & $11(7.4)$ & $5.7(1-10)$ \\
\hline Long-term impact & $9(6.1)$ & $5.5(1-10)$ \\
\hline Experiences on the NICU & $7(4.7)$ & $6.3(5-8)$ \\
\hline Breastfeeding & $35(23.7)$ & $4.6(1-9)$ \\
\hline Pressure to breastfeed & $23(15.5)$ & $5.2(2-9)$ \\
\hline Bad mum for not wanting to breastfeeding & $8(5.4)$ & $4.1(1-7)$ \\
\hline Wanting to breastfeed but not being able to & $4(2.7)$ & $4.5(3-6)$ \\
\hline Changing relationships & $27(18.2)$ & $5.6(1-10)$ \\
\hline Relationship with their partner & $17(11.5)$ & $5.1(1-10)$ \\
\hline Relationships with older children & $4(2.7)$ & $3.3(2-5)$ \\
\hline Uninterested or overbearing family members & $4(2.7)$ & $5.0(1-8)$ \\
\hline
\end{tabular}

${ }^{a}$ Some women wrote about more than one issue so percentages do not total $100 \%$ 